\title{
On the Change of Thematic Openings of Linguistic Journal Articles in Finnish and German
}

\author{
Michael Szurawitzki (Duisburg-Essen/Regensburg)
}

\begin{abstract}
The article summarizes the main findings of a contrastive and diachronic study of a corpus of 109 Finnish and German thematic openings of linguistic journal articles from the periodicals Virittäjä and Beiträge zur Geschichte der deutschen Sprache und Literatur. The methodology used is based on a modification of Fredrickson/Swales (1994).
\end{abstract}

\section{$1 \quad$ Introduction}

This paper deals with the development of the thematic openings of linguistic journal articles in Finnish and German. The analysis period is 1897-2003. By 'thematic opening' we understand the part of an academic journal article which today is normally referred to as 'introduction', 'I.', '1.' or the like. The term 'introduction' is not used, since, in academic journal articles which were written around 1900 it is not - as today - clearly indicated. Researchers interested in analyzing older article introductions thus face the task of themselves finding out and defining how long the thematic opening is etc. Why was an analysis period from 1897 to 2003 selected? This has to do with the media that were analyzed. The Finnish sub corpus was compiled from the journal Virittäjä, which has appeared continuously since 1897 . The German sub corpus respectively was compiled from the Beiträge zur Geschichte der deutschen Sprache und Literatur (subsequently referred to as PBB), appearing since 1874. Thus one could not choose an earlier point in time than 1897 to start the diachronic analysis from. 2003 marks the end of the time frame since my study as a whole (published as Szurawitzki 2011) was designed in early 2005. When I compiled my corpus, the 2003 volumes of Virittäjä and the $P B B$ were the most recent complete volumes of each periodical at the time. My initial goal was to conduct research on the structures and development of the thematic openings in the Finnish and German articles for each language separately. After that, the results were to be compared. This is also the structure of this paper; the analysis, however, is preceded by remarks on the compilation of the corpus and the methodology used.

\section{The Corpus}

The corpus of my study was compiled as follows: First, the periodicals from which the articles for analysis were going to be selected, were chosen. The periodicals had to have (also) a linguistic focus, since the articles to be chosen had to be linguistic ones. Choosing the articles was not always a clear-cut case, since the division between literature and linguistics was not as strict one hundred years ago as it is today. Articles were selected on thematic grounds, however, meaning that the articles were read and identified as linguistic articles prior to selection for the corpus. This took place on the basis that the Virittäjä was the only such option for the Finnish language area, whereas the $P B B$, for the German language area, was the choice with the highest tradition (cf. Storost 2001). Moreover, the $P B B$ provided a larger number of linguistic articles than the Zeitschrift für deutsches Altertum und deutsche 
Literatur $(Z f d A)$, which can look back on a similarly long tradition as the $P B B$. This is why the $P B B$ were ultimately preferred over the $Z f d A$. In the next step, the size of the corpus and the time frame of the analysis were reflected upon. It was clear that from the design of the study and the analysis period ranging from 1897 to 2003, the time intervals between the selected analysis periods were to be held roughly equivalent.

The Nazi period (1933-1945) was to be left out, since the language and style of the academic discourse analyzed was possibly distorted by ideological influences, even though academic language always also was embedded in a concrete sociological and political context ${ }^{1}$ regardless of whether we are looking at a democracy or dictatorship. However, the change implemented by Hitler's ascension to power in Germany must have brought about also significant change in the academic (linguistic) discourse in Germany. This can also be partly assumed as valid for Finland, who were an ally of Germany during World War II. A radical change in academic discourse as brought about by the Nazi regime deserves closest attention since we to this day lack linguistic studies which address this problem. There should be separate studies focusing on the Nazi period and its special linguistic phenomena; this reaches beyond the scope of what my study in the diachronic view wants to provide, namely an overview of the development of the structure of the thematic openings of linguistic journal articles from 1897 to 2003; this development is, if you will, 'interrupted' by an interlude that is the Nazi era. Thus I here prefer to see 1933-1945 tackled in own research projects; I concur with the view that one could possibly find highly relevant information on how dictatorships function linguistically and how ideology could be embedded into academic texts.

Thus, for both languages one should ideally select a maximum of 15 articles per analysis period (see below) which were of linguistic theme (had to analyzed before selection) and were written by a native speaker. The choice of native speakers only was triggered by the assumption that having a language differing from Finnish or German in the background could influence the way one writes unconsciously through the prism of one's (third) native tongue. As analysis periods the following four periods were selected (chronologically): 1897-1903, 1927-1931, 1962-1968, and 1997-2003. The time spans indicate the maximum numbers of volumes needed to go through to select a maximum number of 15 articles fulfilling the selection criteria mentioned above for the respective sub corpora. In some cases, one needed fewer volumes, and for some periods, there were less than fifteen articles fulfilling the criteria. The following table summarizes the composition of the corpus:

\begin{tabular}{|l|l|l|}
\hline & $P B B$ & Virittäjä \\
\hline 1897-1901: & 15 art. & 15 art. \\
\hline 1927-1931: & 11 art. [1930-1931] & 14 art. [1927-1931] \\
\hline 1962-1968: & 14 art. [1962-1968] & 13 art. [1965-1966] \\
\hline 1997-2003: & 12 art. [1997-2003] & 15 art. [2002-2003] \\
\hline$n=109,2430$ pp. \\
\hline
\end{tabular}

Table 1: The Corpus

\section{Methodology}

Within international linguistics, different approaches exist concerning the question of how to characterize the cultural specifics of academic discourse. On the one hand we have researchers, such as Widdowson (1979) or Buhlmann (1985), who postulate certain shared

\footnotetext{
${ }^{1}$ Cf. the works of Ludwik Fleck.
} 
'universal' properties in academic discourse, regardless of its language. On the other hand approaches exist which, in the tradition dating back to Galtung $(1983,1985)$, try to group academic styles according to the region they originate from (e. g. teutonic style).

This paper does not accept a) the 'universal properties' stance since we could hardly analyze thematic openings on the basis of the assumption they functioned universally in a parallel manner in any given language. We rather take the stance that the previously mentioned 'universalia' could only be made visible in a contrastive German-Finnish study by giving way to a dominating theory which quasi dictates the results beforehand. Moreover, there would $b$ ) arise a methodological problem concerning Galtung, whose classification system is not elaborate enough to include a Finno-Ugric language like Finnish, since it focuses on the linguae francae of world academic discourse.

As a hypothesis we can formulate based on Piitulainen (1995) that there are closer relationships between the German and Finnish academic discourses than previously assumed. Academic discourse has not been the subject of contrastive analysis Finnish-German until now, unlike text types such as adverts, obituaries, recipes and the like, which have been the subjects of contrastive analyses. One more gap this study sets out to bridge is the demand by Kalverkämper (1994), reiterated by Ehlich $(1998,2000)$, to broaden the only synchronically operating LSP research in the German language area by tackling also diachronically oriented studies.

Ken Hyland (2000) suggests a model of linguistic analysis of academic texts. It is in line with Flowerdew's statement that research on academic discourse has become "narrower in the sense that it has focused on specific genres, and deeper in so far as it has sought to investigate communicative purposes, not just formal features" (Flowerdew 2002: 2):

"1. Placing the genre-text in a situational context in order to understand why the genre is conventionally written the way it is. 2 . Surveying the existing literature for other perspectives and insights into the situated working of the genre and its conventional form. 3 . Refining the situational/contextual analysis to more clearly identify the goals, participants, network of surrounding texts, and the extra-textual reality that the text is trying to represent. 4. Selecting an appropriate corpus to ensure that it is sufficiently representative of the focus genre to allow the research questions to be explored adequately. 5. Studying the institutional context in which the genre is used in order to better understand the implicit conventions most often followed by participants in that communicative situation. 6. Selecting one or more levels of analysis (lexicogrammatical, textualisation, move structure) to best address the motivating problem. 7 . Obtaining information from specialist informants to confirm findings, validate insights, add psychological reality, and open areas of further exploration." (Hyland 2000: 137)

Hyland's model, which can be considered a starting point for my approach, cannot, however, be used without major modifications. One must (1.) clarify the historical context: this is achieved by providing a historical overview of the relevant time period which focuses on Germany's and Finland's university systems as well as the development of linguistics. This is important, since the Beiträge $(P B B)$ constituted, until the early $20^{\text {th }}$ Century, one of the internationally leading publications in worldwide philology, and one can assume there might have been a modeling of the young Virittäjä on the trendsetter Beiträge $(P B B)$. As a second step, we thoroughly examine the situational context of the articles analyzed such as university surroundings, editors etc. This is achieved by using relevant literature, which is available for the Virittäjä as Juusela (2006) wrote a history on the then one hundred year-old periodical. For the German part, one here needs to use numerous sources to compile the information needed, König's Internationales Germanistenlexikon (3 vols., 2003) and Kürschners Deutscher Gelehrten-Kalender (updated on a regular basis) being valuable means of help. The steps 1 and 2 could not be analyzed in this depth by trying to derive the contexts from the texts themselves since the texts focus on more specialized linguistic questions than providing historical 
overviews. A third step, then, must then aim at an overview of the thematic orientation in terms of discourse context. This is achieved by compiling an index of all research articles published in the Virittäjä and the Beiträge $(P B B)$ and quantitatively analyzing the articles' themes (cf. Szurawitzki 2011: 275-344 for this index). On the basis of steps 1-3, the analysis of the thematic openings itself forms the fourth step. On the basis of such a model one will be able to describe linguistic and cultural as well as historical changes.

The description model to be developed here has as a point of reference a statement by the Finnish linguist Aarni Penttilä (1899-1971). Penttilä is described as a keen critic of the neogrammarians who shaped the development of especially Germanic linguistics during the early period of his academic activity (cf. Hovdhaugen et al. 2000), i. e. roughly from 1920 onwards. The neogrammarians, such as Hermann Paul and Wilhelm Braune, the founders and first editors of the $P B B$, and their paradigms had been highly influential in Germanic linguistics already since the $1870 \mathrm{~s}$. Penttilä criticized the neogrammarian position that solely descriptive linguistics was considered only a 'tool' or merely a means to an end in contrast to historical, i. e. diachronic linguistics. Penttilä states that without a solid descriptive foundation, there could be no historical interpretation in linguistics (Hovdhaugen et al. 2000: 360). We need to take Penttilä's statement into account when examining linguistic articles, especially in Germanic linguistics, since this text type has rarely been the subject of extensive scholarship (cf. Szurawitzki 2008: 250).

Whilst designing the methodology of my study, I discuss relevant methodological approaches which potentially could help shape my own approach. There are studies on the thematic openings of academic journal articles which try to develop models for analysis and/or description. One of the frequently quoted studies of this kind is Swales (1981), which primarily describes a model for the analysis of English language academic articles:

MOVE ONE: Establishing the Field

A) Showing Centrality i) by interest ii) by importance iii) by topic-prominence iv) by standard procedure

B) Stating Current Knowledge

C) Ascribing Key Characteristics

MOVE TWO: Summarizing Previous Research

A) Strong Author-Orientations

B) Weak Author-Orientations

C) Subject Orientations

MOVE THREE: Preparing for Present Research
A) Indicating a Gap
B) Question-Raising
C) Extending a Finding

MOVE FOUR: Introducing Present Research
A) Giving the Purpose
B) Describing Present Research i) by this / the present signals ii) by Move 3 take-up iii) by switching to First Person Pronoun

(Swales 1981: 22)

The problem evident in Swales's model is its highly normative character. Swales presupposes a clear four-move structure of the thematic opening of an academic article. Phenomena such as interlingual and diachronic aspects can hardly be described adequately using this elaborately normative pattern. Especially in the case of earlier articles to be analyzed in future studies, e. g. from the beginning of the $20^{\text {th }}$ Century, one could assume that a structure in Swales's sense is either not given or cannot be described adequately by his model. The 
Michael Szurawitzki: On the Change of Thematic Openings of Linguistic Journal

strength of his model, though, lies in the fact that he has pinpointed elements which can be beneficial to look for. This, however, cannot happen in a normative scheme like Swales's, but one must have more freedom in the descriptive dimension (cf. also Szurawitzki 2008: 252253).

A second study relevant to my research is Lovejoy (1991) who analyzes article introductions from the fields of psychology, biology, and history, and comes to the conclusion that for his relatively small corpus, differing strategies on how to structure information can clearly be identified (Lovejoy 1991: 327). This must be kept in mind when analyzing my results, for we can assume quite significant differences in the structures of the thematic openings in Finnish and German (and the disciplines of Finnish and German linguistics) on the basis of Lovejoy's results.

Busch-Lauer (1997) conducted a contrastive analysis of German and English medical science article introductions. Her results indicate a significantly higher degree of variation of structure within the German introductions, whereas the English introductions tend to be more uniform. Busch-Lauer, in her results, summarizes the key steps of medical article introductions (we see a striking resemblance to Swales's (1981) moves, the moves II and IV are direct 'quotations', even though not indicated as such):

I. Identifying the field of research

II. Summarizing previous research

III. Justifying the author's own research

IV. Introducing present research

(Busch-Lauer 1997: 51)

More relevant research in the field is e. g. Vassileva (2004) on German and Bulgarian economics articles. Her results are of no direct relevance to me, and neither is Graefen/Thielmann (2007), who research articles from the natural sciences. Thielmann (2009), in his skilled Habilitationsschrift, focuses on introductions in German and English academic articles. He identifies different patterns of introduction strategies for the different languages, less convincingly for the German introductions, and in my view without sufficient empirical support, referring to Ehlich/Rehbein (1986) and their Handlungsmuster des Begründens. For the English language introduction of the (only) two analyzed, Thielmann (2009: 55) observes a three-move structure, which clearly resembles the structure in Swales (1990), which serves also as a point of departure for my study. Thielmann, however, does not quote Fredrickson/Swales (1994), which become even more relevant for the approach I eventually choose to describe the article openings.

Fredrickson/Swales (1994: 10) develop further the thoughts published in Swales (1990). Swales characterizes the English language academic article as more persuasive than descriptive. This is due to authors fighting other authors for publication space. The CREATING A RESEARCH SPACE model by Swales (1990: 141) takes this assumption as a point of departure. Certain moves are preferred over others for reasons of competition. Fredrickson/Swales employ a model based on Swales (1990: 141), which has been slightly simplified:

Move 1. Establishing a territory

Move 2. Establishing a niche (By one of four steps: A) counter-claiming, B) indicating a gap, C) question-raising, or D) continuing a tradition, where shifting from A through $\mathrm{D} s$ upposedly Indicates a steady weakening of the knowledge claim.)

Move 3. Occupying the niche

(Fredrickson/Swales 1994:10) 
In extending the approach of Fredrickson/Swales (1994) it seems useful for my corpus to precede the comparative-descriptive analysis with the following steps: Firstly, is the thematic opening clearly marked (i. e. by a heading, by paragraphs, a different typeset, numbering etc.) or not? The second aspect is related to references to secondary literature. Authors often refer to secondary literature, either in the text, for which I will use the short form ' $\mathrm{L}$ ', or in footnotes, which I am going to refer to as '(L)' (=L in parentheses). The use of references has to be indicated in the analysis at the relevant position of the thematic opening. The description is supplemented by details concerning length and overall structure of the articles analyzed as well as the average length of the sub corpus' articles.

The analysis model for thematic openings chosen here works as follows: the first step is to determine the thematic orientation of the article analyzed, which is abbreviated as ' $\mathrm{T}$ ' (from Swales's territory). In modifying Fredrickson/Swales (1994) we must determine whether this is done explicitly (short form 'e') or implicitly (short form 'i'). This is an important criterion for the selected corpus, as we have very long (over 100 pp.) articles as well as rather short ones (1-2 pp.). The differing article lengths might cause irritation at first, since one might assume that completely different text types would be assumed as being one. This is, however, not the case. The articles analyzed belong to the text type 'linguistic article' since they are published in the periodicals analyzed. A thematic reading has determined that they include original research and thus are suitable for inclusion into my corpus. The variation is much higher for the older articles; as we proceed towards our times at the beginning of the $21^{\text {st }}$ Century, this variation is no longer existent. I thus deem it necessary to take this variation, which naturally has implications also for the structure of the thematic openings, into consideration. The variation can be characterized as rather dependent on conventional change in conventions of cultural or academic history rather than simply saying that we are looking at different text types.

As a second step we need to analyze if the author formulates his 'niche' (short form 'F'). Here we have to also distinguish between explicit and implicit. For the interpretation, how the author formulates his niche has to be analyzed. Using a strict A-D pattern, as in Fredrickson/Swales (1994: 10) does not seem useful for my study. Namely, we cannot be sure if a background of fighting for publication space, such as Swales (1990) describes, exists for the $P B B$. Here it might be slightly different, since no further studies exist which elaborate on this aspect. Since the scope of the $P B B$ has traditionally been rather specialized, one might assume - speculatively - that the number of relevant manuscript submissions and resulting subsequent publications were/are significantly smaller than e. g. in leading, exclusively English language contemporary linguistic periodicals. As a thirdly, it has to be analyzed whether there is a concrete formulation of the article's aim (short form ' $\mathrm{K}$ ' from German Konkretisierung). As in steps 1 and 2 we have to distinguish between explicit and implicit. My model describes as a fourth step the sequence in which these elements occur to make comparisons, both synchronically and diachronically, possible (cf. also Szurawitzki 2008: 255-256, passim).

\section{$4 \quad$ Results}

The results will be presented in separate sections, starting with the Virittäjä, then followed by the $P B B$. We will confine our observation, as stated in the beginning, to the diachronic development of the thematic openings. Now how can one summarize the findings of article-perarticle, opening-per-opening analyses? This can be done by introducing the concept of the socalled 'dominant version' [dominante Version] and the sub-version. What I call a dominant version within the boundaries of my study is a structural pattern of thematic opening recurring at least three times in the relevant sub corpus analyzed. A sub-version bears a high similarity to a dominant version, the only difference being a variation concerning the use of references 
to secondary literature, otherwise the structure of the thematic opening is exactly like the dominant version related to the sub-version.

I thus analyze the diachronic development of the thematic openings by analyzing the change on the basis of evaluating the change in the dominant versions. Even though this might sound in a way like simplifying things, this is in my view the only way to systematically assess the diachronic development of the thematic openings in a fairly large corpus like mine. The focus is to show the main tendencies in this development, and this is attempted by assuming a perspective enabling us to see the 'bigger picture', i. e. here the structural change in thematic openings taking place over a time span of over 100 years. The results of the empirical analyses of the individual thematic openings can due to reasons of limited publication space not be presented here, but they will appear in a future separate monograph publication.

In the following section the dominant and sub-versions of the thematic openings as found for both Virittäjä and $P B B$ are presented. In the relevant tables first a tagging is given, which is then also explained in prose. The numbers preceding the explanation indicate the sequence of occurrence of the relevant element of the opening in the diachronic perspective that is assumed here. This shall serve the purpose of providing a system to possibly better describe the change taking place in the opening structures.

\subsection{The Development of Thematic Openings in the Virittäjä}

In the following table the results of the diachronic development of the thematic openings in my Virittäjä corpus are summarized:

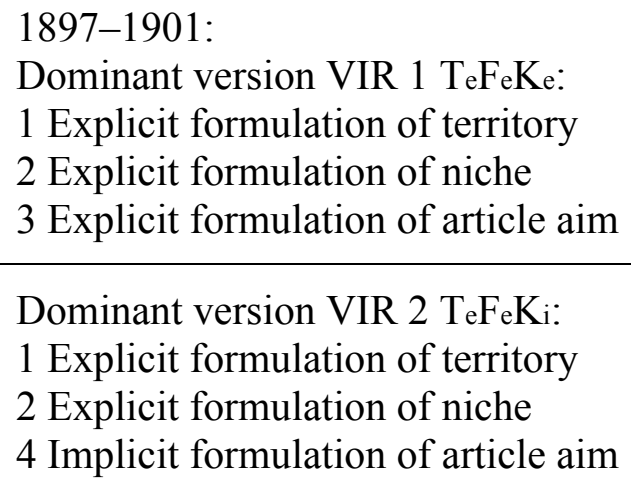




\begin{tabular}{|l|}
\hline 4 Implicit formulation of article aim \\
\hline 1965-1966: \\
Dominant version VIR $2 \mathrm{TeF}_{\mathrm{e}} \mathrm{i}:$ \\
1 Explicit formulation of territory \\
2 Explicit formulation of niche \\
4 Implicit formulation of article aim \\
\hline 2002-2003: \\
Dominant version VIR 4 TeLFeKeL(L): \\
1 Explicit formulation of territory \\
5 References to secondary literature in text \\
2 Explicit formulation of niche \\
4 Explicit formulation of article aim \\
5 References to secondary literature in text \\
6 References to secondary literature in footnotes \\
\hline
\end{tabular}

Table 2: The Dominant Versions of Thematic Openings for the Analyzed Virittäjä Subcorpora

For the period 1897-1901, we have two dominant versions of thematic openings (VIR 1 and VIR 2) with the sub-version VIR 2a. For both VIR 1 and VIR 2 we have a parallel in the explicitly formulated territories and niches. VIR 2 can be found also in the following analysis period, i. e. 1930-1931, whereas VIR 1 cannot be found. Instead, we find VIR 3, which, as VIR 1 before, does not occur in the later periods. The influence of VIR 2 continues in the 1965-1966 analysis period, since no other dominant versions can be found here. The change from VIR 2 to VIR 4 in 2002-2003 seems at first glance rather strong. We thus research what the elements of this transition are. Elements to be found in both dominant versions are the explicitly formulated territories and niches. VIR 4 mainly thus differs from VIR 2 through its pattern of references to secondary literature. While we have no references in VIR 2, in VIR 4 there are references (in the text) first after the explicitly formulated territory, and then after the explicitly formulated article aim, first in the text, and then, concluding the opening, in footnotes.

When we now try to summarize the development of the thematic openings for my Virittäjä corpus over time, we can state that beginning with VIR 1, via the in three of the four analysis periods influential VIR 2, to VIR 3 and ultimately VIR 4, there has occurred a significant change in the structure of the thematic openings. The diachronic analysis has indicated that we can consider the explicitly formulated territories and niches (1-2) the 'core elements' of the thematic openings. They basically stand close to one another in the initial part of the thematic opening. This is first broken up in VIR 2 by the insertion of references to secondary literature in the text between them. This 1-5-2 pattern remains also in VIR 4. In VIR 3 the article aim is formulated implicitly, whereas the development towards VIR 4 indicates an explicit formulation of this element of the opening. If we now try to contextualize these results against the background of Gross et al.'s (2002: 230) results which found a tendency towards a uniformity in their analysis of academic articles, the following remarks can be made: on the one hand we can detect a notion of uniformity via VIR 2, on the other hand the uniformity shifts out of the focus through VIR 3 and, ultimately, VIR 4. One, however, has to note that Gross et al. (2002) make their observations on the basis of a corpus of academic articles written in present-day English. One might assume that English as the global lingua franca of academia has had its share in the development observed in this study, but it would take further efforts, with English openings as the subject of study, to verify this hypothesis. 
Michael Szurawitzki: On the Change of Thematic Openings of Linguistic Journal

\subsection{The Development of Thematic Openings in the $P B B$}

In the following table the results of the diachronic development of the thematic openings in my $P B B$ corpus are summarized:

1897-1901:

Dominant version PBB $1 \mathrm{TeFeLKe}[\mathrm{L}]$ :

1 Explicit formulation of territory

2 Explicit formulation of niche

3 References to secondary literature in text

4 Explicit formulation of article aim

[3] [optionally: References to secondary literature in text]

Dominant version PBB $2 \mathrm{TeFeLK}$ :

1 Explicit formulation of territory

2 Explicit formulation of niche

3 References to secondary literature in text

5 Implicit formulation of article aim

Dominant version PBB 3 LTeFiKi:

3 References to secondary literature in text

1 Explicit formulation of territory

6 Implicit formulation of niche

5 Implicit formulation of article aim

1927-1931:

Dominant version PBB 4 TeLFeKi:

1 Explicit formulation of territory

3 References to secondary literature in text

2 Explicit formulation of niche

5 Implicit formulation of article aim

1962-1968:

Dominant version PBB $5 \mathrm{TeFe} \mathrm{Ke}(\mathrm{L})$ :

1 Explicit formulation of territory

2 Explicit formulation of niche

4 Explicit formulation of article aim

7 References to secondary literature in footnotes

1997-2003:

Dominant version PBB $6 \mathrm{Te}$ (L)/L FeKe:

1 Explicit formulation of territory

3 References to secondary literature in text or

7 References to secondary literature in footnotes

2 Explicit formulation of niche

4 Explicit formulation of article aim

Sub-version $6.1 \mathrm{Te}$ (L) FeKe:

1 Explicit formulation of territory

7 References to secondary literature in footnotes

2 Explicit formulation of niche

4 Explicit formulation of article aim 


\author{
Sub-version 6.2 Te L FeKe: \\ 1 Explicit formulation of territory \\ 3 References to secondary literature in text \\ 2 Explicit formulation of niche \\ 4 Explicit formulation of article aim
}

Table 3: The Dominant Versions of Thematic Openings for the Analyzed PBB Subcorpora

In the analysis period 1897-1901, we find the dominant versions PBB 1 - PBB 3. These do not occur in the following period, i. e. 1927. Instead, there occurs the dominant version PBB 4. PBB 4 is highly similar to PBB 2 and only differs through the differing position of references to secondary literature used in the text. When then proceeding to 1962-1968, one finds that the former dominant versions are no longer relevant, instead PBB 5 dominates here. PBB 5 in turn is for 1997-2003 replaced by PBB 6, with the sub-versions PBB 6.1 and PBB 6.2.

In terms of analyzing the development of the thematic openings in the $P B B$ sub corpora over time, the following remarks can be made based on the dominant versions: We seem to have a development from a rather obvious heterogeneity (cf. three differing dominant versions, PBB 1- PBB 3, in 1897-1901) to more homogeneity. In 1927-1931 (PBB 4) and 1962-1968 (PBB 5) we have one dominant version respectively. Similarly as for the Virittäjä sub corpora, one can describe the change in the structure of the thematic openings departing from the 1-2 structure, i.e. the explicit formulation of the territory and the explicit formulation of the niche. While we find this structure in PBB 1 and PPB 2, it cannot be found in PBB 3. The second remark concerns the formulation of the article aim: while PBB 1 has an explicitly formulated aim, PBB 2, PBB 3 as well as PBB 4 (1927-1931) have implicit formulations respectively. This textual strategy of implicitly including the article aim in the thematic opening can thus be interpreted as possibly being somewhat 'common practice', even though one must not forget that the results presented here are primarily valid for the corpus and only might have implications on a broader scale (which is subject to veri- or falsification; see also 5 below). In PBB 5 we once again find the 1-2 structure in the beginning of the thematic opening; here we also have an explicit formulation of the article aim. Here we also have the first occurrence of references to secondary literature in footnotes.

One can state an increasing uniformity of the thematic openings in the $P B B$ subcorpus. The explicit formulation of the territory is constant. The niche shifts from implicit or explicit formulation (implicit in PBB 3; explicit in PBB 1 and PBB 2) towards explicit formulation (PBB 4, PBB 5, PBB 6). The article aim is mostly formulated implicitly at first (PBB 2, PBB 3, PBB 4) also shifts towards an explicit formulation (PBB 5, PBB 6).

\title{
5 Conclusions and Perspectives for Further Research
}

We begin our summary with the development of the thematic openings in the Virittäjä sub corpora. Here it can be stated that, quantitatively, the dominant version VIR 2 has a significant position since it occurs in three of the four periods analyzed. For the $P B B$ sub corpora there does not exist a dominant version that could be called correspondent to VIR 2 . The dominant versions PBB 1 - PBB 5 and PBB 6 with the sub-versions PBB 6.1 and PBB 6.2 coexist in a state of relative equality, when we look at the quantitative occurrence. Due to the higher number of dominant versions within the German sub corpora, one could assume a higher tendency of variation for the German thematic openings, also given that there is a notion of more homogeneity within the Finnish dominant versions than in their German counterparts, even though also within the German openings a shift towards more uniformity has been detected. The higher heterogeneity within the German openings might also be explained by the higher number of authors writing in German, thus providing more variation 
than the limited number of Finnish academic authors. One more reason might lie in different 'schools' or 'tradtions' that might have been established earlier and in higher number for German academia than for its Finnish counterpart. This might be explained by a more differentiated language culture which had a long time to develop in Germany, diametrically opposed to the very young academic language that is Finnish, only dating back to the second half of the $19^{\text {th }}$ Century.

On the whole, one can state that Finnish, even if German might serve as the model, takes an own path. My results can neither indicate nor completely deny a direct influence that the structure of the German thematic openings might have had on the Finnish openings (cf. Szurawitzki 2011: 247-265) for an elaborate summary of the results; this would go beyond the scope of this article.

Concerning future research, it seems highly relevant to point out - as has been stated above that there should be efforts, using larger corpora than mine, to prove or disprove the results presented here. One needs to learn more on the diachronic impact of German as one of the past leading languages of academia - and its lesser and lesser impact since World War II. In this context the role of French, it being also an academic language of former high prestige, should be investigated on diachronic terms.

It is, however, also important to include English thematic openings in future synchronous corpus studies, since they constitute a common denominator through being written in the global academic lingua franca of our time. By including English as an important tertium comparationis, at least from today's perspective, one could thus make possible a successful transfer of the research results laid down in this paper and globalize the discussion of individual thematic openings' structures in individual academic languages and disciplines. The 'discipline' factor has been left out here altogether, but it goes without saying that there is a need to investigate the differences in various disciplinary discourses as well. As this study has tried to indicate for Finnish and German, there seems to be a fairly high degree of individuality when it comes to formulating academic discourse. A 'universal' perspective is hard to assume in the light of the results presented in this paper.

\section{Bibliography}

Buhlmann, Rosemarie (1985): "Merkmale geschriebener und gesprochener Texte im Bereich naturwissenschaftlich-technischer Fachsprachen. Eine Betrachtung unter didaktischen Gesichtspunkten." Fachsprache 1/2: 98-122.

Busch-Lauer, Ines (1997): "Schreiben in der Medizin. Eine Untersuchung anhand deutscher und englischer Fachtexte." In Jakobs, Eva.-Maria./Knorr, Dagmar (eds.): Schreiben in den Wissenschaften. Frankfurt a. M.: 45-62.

Ehlich, Konrad (1998): "Kritik der Wissenschaftssprachen." In: Hoffmann, Lothar et al. (eds.): Fachsprachen. Ein internationales Handbuch zur Fachsprachenforschung und Terminologiewissenschaft. Berlin/New York: 856-865.

Ehlich, Konrad (2000): "'Wissenschaftsstile', Wissenschaftssprache und ihre (wissens-) soziologischen Hintergründe." In: Deminger, Szilvia et al. (eds.): Einstellungsforschung in der Soziolinguistik und Nachbardisziplinen/Studies in Language Attitudes. Frankfurt: 59-71.

Fredrickson, Kirstin/Swales, John (1994): "Competition and Discourse Community: Introductions from Nysvenska studier." In: Gunnarsson, Britt-Luise et al. (eds.): Text and Talk in Professional Contexts. Uppsala: 9-21.

Galtung, Johan (1983): "Struktur, Kultur und intellektueller Stil." Leviathan 3: 303-338.

Galtung, Johan (1985): "Struktur, Kultur und intellektueller Stil. Ein vergleichender Essay über sachsonische, teutonische, gallische und nipponische Wissenschaft." In: Wierlacher, Alois (ed.): Das Fremde und das Eigene. München: 151-193. 
Graefen, Gabriele/Thielmann, Winfried (2007): "Der Wissenschaftliche Artikel." In: Auer, Peter/Baßler, Harald (eds.): Reden und Schreiben in der Wissenschaft. Frankfurt/New York: 67-97.

Hovdhaugen, Even et al. (2000): The History of Linguistics in the Nordic Countries. Jyväskylä.

Kalverkämper, Hartwig (1994): "Diachrone Fachsprachenforschung - Plädoyer für eine Öffnung in neue Perspektiven." In: Spillner, Bernd (ed.): Fachkommunikation. Frankfurt et al.: $15-31$.

König, Christoph (ed.) (2003): Internationales Germanistenlexikon 1800-1950. 3 vols. Berlin/New York.

Lovejoy, Kim Brian (1991): "Cohesion and Information Strategies in Academic Writing: Analysis of Passages in Three Disciplines." Linguistics and Education 3.4: 315-343.

Piitulainen, Marja-Leena (1995): "Aspekte der kontrastiven Textanalyse Deutsch-Finnisch." Finlance 15: 35-53.

Storost, Jürgen (2001): "Die ,neuen Philologien', ihre Institutionen und Periodica: Eine Übersicht". In: Anroux, Sylvain et al. (eds.): Geschichte der Sprachwissenschaften. Ein internationales Handbuch zur Entwicklung der Sprachforschung von den Anfängen bis zur Gegenwart. 2. Teilband. Berlin/New York: 1240-1272.

Swales, John (1981): Aspects of Article Introductions. Birmingham.

Swales, John (1990): Genre Analysis: English in academic and research settings. Cambridge.

Szurawitzki, Michael (2008): "Analyzing the Thematic Openings of Linguistic Journal Articles - Developing a Methodology and Examining a Corpus Compiled from the Beiträge zur Geschichte der deutschen Sprache und Literatur." Revista de Filología Alemana 16: 249-260.

Szurawitzki, Michael (2011): Der thematische Einstieg. Eine diachrone und kontrastive Studie auf der Basis deutscher und finnischer linguistischer Zeitschriftenartikel. Frankfurt a. M. et al. (= Duisburger Arbeiten zur Sprach- und Kulturwissenschaft 85)

Thielmann, Winfried (2009): Deutsche und englische Wissenschaftssprache im Vergleich. Hinführen - Verknüpfen - Benennen. Heidelberg.

Vassileva, Irena (2004) "Der wirtschaftswissenschaftliche Artikel im Deutschen und Bulgarischen. Eine diachrone Perspektive." In: Baumann, Klaus-Dieter/Kalverkämper, Hartwig (eds.): Pluralität in der Fachsprachenforschung. Tübingen: 461-480.

Widdowson, Henry G. (1979): Explorations in Applied Linguistics. Oxford. 